\section{Franco Lo Presti Seminerio Dados Biográficos}

Franco Lo Presti Seminerio nasceu em Turim, Itália, em janeiro 1923. Terceiro filho do engenheiro Decenzio e Laura Lo Presti Seminerio, aos seis anos muda-se com a família para Gênova, e aí faz o primário, o secundário e o liceu no colégio dos Jesuítas, cursando depois Letras, em uma Universidade do século XIII e concluindo o doutorado em 1946 com uma tese em literatura portuguesa, sobre Antero de Quental. Paralelamente, utilizando um recurso que a lei permitia, somando disciplinas facultativas e complementares, conclui também o curso de Filosofia. Atravessou o período da segunda guerra mundial em situações de perigo por ter sido convocado e, por convicção humanitária, desertado. A situação do pós-guerra afigurou-se crítica para quem não dispunha de nenhum passado militar e foi nesse momento que resolveu emigrar para o Brasil, tendo aqui já a irmã mais velha, casada com um colega de infância, Carlos Sparano, e o domínio da língua, pois sua avó materna era portuguesa e convivera com a família.

Chega ao Brasil em 1947 e tenta revalidar seus títulos. Sem problemas quanto a ensino secundário, fez três provas no Colégio Pedro II, envolvendo história e geografia do Brasil, língua e literatura portuguesa e brasileira, o que lhe deu, de imediato, a equivalência ao terceiro ano científico. Em junho de 1954 obteve a nacionalidade brasileira, através de um decreto assinado por Getúlio Vargas e Tancredo Neves. A revalidação do seu doutorado, primeiramente concedida pela congregação da Faculdade Nacional de Filosofia, foi bloqueada pela Reitoria da Universidade do Brasil e o processo extraviado com diploma original e tese; isto o levou a trabalhar em atividades comerciais, ministrando esporadicamente algumas aulas até 1962.

\section{Os primórdios da docência}

Paralelamente, iniciou suas atividades em Psicologia aplicada, voluntariamente, no Centro Juvenil de Orientação e Pesquisa (Ce.J.O.P.) ligado, indiretamente, à Faculdade Fluminense de Filosofia e em 1959 foi-lhe permitido matricular-se no curso de Orientação Educacional, nível de pós-graduação, com base no diploma de doutor, mesmo estando este pendente de revalidação. Graças à informação e orientação de uma colega, Maria Luiza Teixeira de Assumpção - com quem viria a se casar em dezembro 1961 - pôde inscrever-se para as provas de suficiência da antiga CADES, obtendo o primeiro registro formal para lecionar no país.

Em 1962, foi convidado para lecionar no curso recém criado de Orientação Educacional e, em abril desse mesmo ano, o Dr. Francisco Campos o chamou para ingressar no Instituto de Orientação e Seleção Profissional (I.S.O.P.) da Fundação Getúlio Vargas, sob a direção de Emílio Mira Y Lopez. Em 15 de julho desse ano (1962) é efetivado professor da Universidade Federal Fluminense.

Sancionada em agosto de 1962 a lei 4119 , que regulamentava a profissão de psicólogo, prontamente requereu, juntamente com Maria Luiza, o registro pelo artigo 21, face às atividades que ambos já vinham exercendo. Apesar desse direito, já garantido, ambos resolveram submeter-se ao exame vestibular para o primeiro curso de Psicologia, na Faculdade Nacional de Filosofia da antiga Universidade do Brasil. No entanto, ao concluir o quarto ano, com bacharelado e licenciatura, foi convidado a passar de aluno a professor, pois já dispunha de formação universitária completa e experiência prática para instalar a cadeira de Técnicas de Exame e Aconselhamento Psicológico, que passaria a reger até sua aposentadoria compulsória (1993). Mesmo assim, ainda iria cursar o quinto ano na Universidade do Estado, em 1972.

Em 1968 foi convidado pelo diretor da Faculdade de Educação da UFRJ, Professor Raul Bittencourt a transferir-se da U.F.F. para a UFRJ, a fim de assumir a chefia do Departamento de Psicologia da Educação, em fase de organização, cargo que exerceria até 1974. Em seguida, foi professor fundador do curso de Mestrado em Educação nessa faculdade.

\section{A Pesquisa e a Pós-Graduação}

No ISOP assumiu, em 1968, a chefia da Divisão de Ensino e Pesquisa, dando início a uma ampla investigação sobre reabilitação profissional, no 
intuito de definir as tarefas acessíveis a portadores de deficiências físicas, perceptuais e mentais; o passo seguinte consistiu na criação de uma metodologia específica de análise do trabalho, incluindo visitas in loco a 1.253 grandes e médias indústrias, para avaliar as limitações mentais e competências requeridas na execução de tarefas, utilizando-se, pela primeira vez em Psicologia do Trabalho, a teoria de Piaget, o qual ao receber, em mãos, uma síntese da pesquisa, o confirmou.

Em abril de 1970 foi nomeado diretor do ISOP, cargo que exerceu até junho 1990 , quando este instituto é extinto pela FGV. Sua primeira decisão, como diretor, foi criar uma comissão para planejar e implantar um curso de Mestrado, da qual participou pessoalmente indicando para compô-la os professores Wedher Modenezi Wanderl, José Figueiredo Cavaliere, Antõnio Gomes Penna, Eliezer Schneider e Aroldo Rodrigues; e para presidi-la convidou o Professor Lourenço Filho.

O segundo passo consistiu na elaboração de um plano para transformação do ISOP de órgão prestador de serviços em órgão normativo em Psicologia, voltado para o ensino de pós-graduação e a pesquisa. A trarsformação, aprovada pela Fundação Getúlio Vargas, resultou na criação de três centros de estudos e pesquisas aplicadas ao trabalho, à educação, à informação ocupacional e à pós-graduação (CEPPAT, CEPPAE, CIPO E CPGP), além da consolidação do centro já existente de estudo e construção de testes (CETPP).

Idealizou, a seguir, um macro projeto, chamado de Diagnóstico Nacional de Desenvolvimento Educacional, realizado em todos os Estados da Federação (dois apenas não participaram) para avaliar o nível de escolarização dos estudantes secundaristas brasileiros. Foram submetidos à verificação individual, em campo, através de provas objetivas, além de questionários, cerca da 40.000 estudantes, selecionados para compor amostras significativas de cada Estado. Esta pesquisa permitiu avaliar o grau de preparo dos alunos dos diversos cursos existentes ( $\mathrm{Ci}$ entífico, Clássico, Técnico, Normal, Industrial), comparando-se os resultados a partir do tipo de ensino, se Público, Particular, Diurno, Noturno, da situação familiar e das motivações explicitadas nas provas realizadas. O planejamento, a coordenação e a execução foram confiados ao Dr.Francisco Campos, então chefe do CETPP.

Paralelamente veio coordenando a editoração da Revista Arquivos Brasileiros de Psicologia, criada por Emílio Myra y Lopes, em 1949, numa luta constante para manter sua qualidade, pertinência e periodicidade, tendo muito presente a idéia de que ela representava uma das poquíssimas possibilidade de registro da produção científica na área no Brasil.

Entrementes realizou uma viagem, junto com Maria Luiza, para entrar em contato com centros europeus de Ergonomia, visando implantar essa nova tecnologia no país. Em 1971 o curso de Mestrado começou a funcionar e uma das três áreas de concentração envolvia a Ergonomia. Para promover a divulgação desta tecnologia, de alto significado social, planejou e executou entre 9 e 14 de setembro 1974, um Seminário Nacional, presidido pelo ministro do trabalho, visando reunir os poucos pioneiros já existentes no Brasil e convidando, além dos brasileiros, especialistas da América Latina, figuras de destaque internacional. Criou no ISOP um centro de Ergonomia, indicando para chefiá-lo o Professor Ued Martins Maluf. Posteriormente, planejou e supervisionou uma pesquisa interinstitucional em Ergonomia, no país, para avaliar e modificar corretivamente, em campo, o penoso trabalho do plantio e corte da cana de açúcar. Como resultado, após quatro anos de investigações sobre os danos e riscos para a saúde do trabalhador, conseguiu-se a proibição do uso dos organo-mercuriais nessa atividade.

Como uma seqüência natural do mestrado, em 1977 criou no ISOP um doutorado, inspirado nos moldes britânicos, inteiramente personalizado e que veio a ser o primeiro na área da Psicologia aprovado pelo Conselho Federal de Educação.

Uma outra linha de pesquisa, mais pessoal, veio sendo desenvolvida desde 1962 , com um projeto inicialmente teórico, que visava descrever os determinismos essenciais da cognição humana, partindo do hiato encontrado na Crítica da Razão Pura de Kant entre número e fenômeno; e a despeito do veto deste filosofo para abordar empiricamente essa fronteira, encaminhou a investigação em termos de linguagens fenomenológicas, que o levou à criação 
de um modelo hipotético e à busca de realização de uma nova tese de doutorado; no entrecruzamento de atividades, em 1973 e 74 estabeleceu contatos com a Universidade de Genova (Itália) a fim de completar seus estudos em Filosofia. Face ao currículum apresentado obteve isenção de frequiência submetendose apenas às provas (10 ao todo) e à defesa de tese que versou sobre o modelo criado, sendo aprovada com louvor. Atualmente trata-se de um modelo teórico já apresentado em diversos congressos internacionais, bem com através de uma série de publicações, sendo que em 1976, a comunicação em Paris de J.Flavell sobre metamemória permitiu-lhe entender que estaria realizando uma investigação metacognitiva.A partir desse momento dirigiu suas investigações para a psicopedagogia visando validar o modelo, obtendo na área da lógica infantil e do desenvolvimento do vocabulário, resultados experimentalmente significativos.

Este segundo título de doutor, diferentemente do primeiro, foi revalidado com toda a brevidade pela UFRJ. No ano seguinte (1975) requereu inscrição em concurso de livre-docência, logrando aprovação plena. Em 1977 inscreveu-se em concurso para professor titular, no Instituto de Psicologia da UFRJ no qual foi aprovado e sucessivamente empossado.

Há ainda uma outra linha de investigação a que se dedica há mais de 50 anos. Trata-se do estudo dos determinantes psicológicos subjacentes às principais religiões existentes no mundo e que deve gerar um livro, lavrado dentro de uma postura neutralmente agnóstica.

A extinção do ISOP , a Pós-Graduação e a Arquivos Brasileiros de Psicologia

Em 26 de junho de 1990 a Fundação Getúlio Vargas extinguiu o ISOP, juntamente com outros sete órgãos. Prontamente requereu ao Presidente da Fundação e ao Reitor da UFRJ a transferência dos cursos de mestrado e doutorado, por ele criados, para o Instituto de Psicologia da UFRJ. Após complexa negociação com o apoio do Conselho Federal de Educação e da CAPES a transferência foi concretizada em 8 de novembro de 1991. Juntamente obteve a transferência da Revista Arquivos Brasileiros de
Psicologia, a mais antiga da América Latina, da qual continuou como editor. Conseguiu transferir também o projeto metacognitivo, que passou a ser apoiado pelo $\mathrm{CNPq}$ como projeto integrado, classificado como 1-A, por este órgão de fomento.

Após sua aposentadoria obteve do Conselho Universitário o título de Professor Emérito, que the permitiu continuar a lecionar na Pós-Graduação e na Graduação, bem como exercer a coordenação, durante anos, do Programa de Pós-Graduação, com os cursos de doutorado e mestrado, além da editoração da revista Arquivos Brasileiros de Psicologia.

É justa a homenagem ao Professor Emérito Franco Lo Presti Seminerio, dedicando-lhe este Número Especial da Cadernos de Psicologia e Educação Paidéia. Está-se diante de um homem que assumiu uma nova pátria e deu a ela todo o seu potencial de trabalho, de maneira incessante e criativa, como quem busca deixar às gerações mais novas caminhos seguros e bem traçados para o desenvolvimento de toda uma área de conhecimento.

Como diz a canção, professor:

\section{"Só nos resta aprender"}

tendo no senhor um exemplo de princípios e de sabedoria. 
182 